\title{
Avaliação on-farm dos níveis de energia na dieta sobre a produção e a composição físico-química de leite de cabras
}

\author{
[On farm evaluation of the energy levels in the diet on the production and physical-chemical \\ composition of dairy goats] \\ S.L.A. Vicente ${ }^{1}$, D.M. Nogueira ${ }^{2 *}$, T.V. Voltolini ${ }^{2}$, S.M. Yamamoto ${ }^{3}$, \\ E.S. Lopes Júnior ${ }^{3}$, S.A. Moraes ${ }^{2}$ \\ ${ }^{1}$ Aluno de pós-graduação - Bolsista da Facepe - Universidade Federal do Vale do \\ São Francisco (Univasf) - Petrolina, PE \\ ${ }^{2}$ Embrapa Semiárido - Petrolina, PE \\ ${ }^{3}$ Universidade Federal do Vale do São Francisco (Univasf) - Petrolina, PE
}

\section{RESUMO}

Objetivou-se, com este estudo, avaliar o efeito de dietas com diferentes níveis de energia no consumo de nutrientes, na produção e na composição do leite, no peso corporal e na relação benefício:custo de uma produção de cabras leiteiras. Foram utilizadas nove cabras, distribuídas em quadrado latino triplo $3 \times 3$. O ensaio teve duração de 60 dias, divididos em três períodos de 20 dias. Avaliaram-se rações completas contendo três níveis de energia: $65 \%, 70 \%$ e $75 \%$ de NDT. Os consumos de matéria seca, proteína bruta e matéria mineral foram superiores $(\mathrm{P}<0,05)$ nas dietas com maiores níveis de energia em comparação à dieta com $65 \%$ de NDT. A produção de leite foi semelhante $(\mathrm{P}>0,05)$ nas cabras recebendo dietas contendo $70 \%$ e $75 \%$ de NDT, todavia foi superior $(\mathrm{P}<0,05)$ à produção de leite das cabras recebendo dieta com $65 \%$ de NDT. A dieta com $75 \%$ de NDT possibilitou maior $(\mathrm{P}<0,05)$ peso corporal final, quando comparada com as dietas contendo $65 \%$ e $70 \%$ de NDT. Não foi observada diferença $(\mathrm{P}>0,05)$ para os parâmetros físico-químicos de gordura, lactose, proteína bruta, extrato seco desengordurado, densidade, sais e condutividade do leite. Portanto, cabras alimentadas com níveis de energia entre $70 \%$ e $75 \%$ de NDT na dieta total aumentam a produção de leite, porém 75\% de NDT na dieta proporciona melhor relação benefício:custo, havendo, para cada $\mathrm{R} \$ 1,00$ no custo investido na alimentação, $\mathrm{R} \$ 1,52$ de retorno financeiro.

Palavras-chave: cabra leiteira, caprino, nutrição, produtividade

\begin{abstract}
The objective of this study was to evaluate the effect of diets with different energy levels on nutrient intake, milk production and composition, body weight and benefit:cost ratio of a dairy goat production. Nine goats were distributed in a triple $3 \times 3$ latin square design. The experiment lasted for 60 days, divided into three 20-day periods. Complete rations containing three energy levels were evaluated: 65\%, $70 \%$ and $75 \%$ of TDN. The dry matter intake, crude protein and mineral matter consumption were higher $(P<0.05)$ in the diets with higher levels of energy compared to the diet with $65 \%$ of TDN. Milk production was similar $(P>0.05)$ in goats receiving diets containing $70 \%$ and $75 \%$ TDN, but these diets produced more milk $(P<0.05)$ than the diet with $65 \%$ of TDN. The diet with $75 \%$ of TDN allowed a higher $(P<0.05)$ final body weight $(P<0.05)$ when compared to diets containing $65 \%$ and $70 \%$ TDN. There was no difference $(P>0.05)$ in the physical-chemical parameters of fat, lactose, crude protein, defatted dry extract, density, salts and conductivity of the milk. Therefore, goats fed with diets of $70 \%$ and $75 \%$ of TDN in the total diet increased milk production. However, the diet with $75 \%$ of TDN provides a better benefit:cost ratio, as for every \$1.00 in the cost invested, there was \$1.52 of financial return.
\end{abstract}

Keywords: dairy goat, does, nutrition, productivity

Recebido em 27 de fevereiro de 2019

Aceito em 18 de outubro de 2019

*Autor para correspondência (corresponding author)

E-mail: daniel.nogueira@embrapa.br 


\section{INTRODUÇÃO}

A caprinocultura leiteira representa um importante papel econômico na pecuária nordestina e, na maioria dos casos, é a principal geradora de renda para produtores rurais da região semiárida do nordeste brasileiro. Porém, na região Nordeste, a maioria da produção de leite de cabra é de subsistência, consumida próximo aos locais de produção, e possui um nível de organização social muito débil e dependente do apoio governamental, como o Programa de Aquisição de Alimentos (PAA).

O leite de cabra é um alimento que possui alto valor biológico e é conhecido por conter os elementos necessários à nutrição humana, como lactose, proteínas, gorduras, vitaminas, ferro, cálcio, fósforo e outros minerais. Além disso, o leite de cabra apresenta características de hipoalergenicidade, devido às características das caseínas presentes em sua composição, e alta digestibilidade, devido à maior proporção de glóbulos de gorduras de menor tamanho, pela presença de ácidos graxos de cadeia curta (Costa et al., 2009). Dessa forma, esse produto é bastante recomendado para a alimentação de idosos, crianças e pessoas intolerantes ao leite de vaca ou ao leite materno (Araújo et al., 2012).

Diversos fatores influenciam na produção e na qualidade do leite de cabra, entre os quais se pode citar: raça, idade, estádio de lactação, sanidade, estação do ano e alimentação (Vilar et al., 2008). Sem dúvida, a alimentação é o principal fator de importância técnicoeconômica, pois representa a maior parte dos custos de produção e pode impactar na produção e na composição do leite.

A energia é o componente da exigência nutricional que mais está relacionado ao desempenho produtivo dos animais. Com o objetivo de aumentar a produtividade dos animais, alguns autores testaram diferentes níveis energéticos nas dietas durante a lactação de cabras leiteiras. Por exemplo, Goetsch et al. (2001) concluíram que dietas com maiores níveis de energia metabólica promovem maior produção de leite em cabras Alpinas. Segundo Zambom et al. (2005), os níveis de energia em dietas de cabras de leite alteram a ingestão de matéria seca, produção e composição físico- química do leite, pico e persistência da curva de lactação.

Foi observada a carência de informações sobre a utilização de dietas com diferentes níveis de energia e seus impactos na produção de leite de cabras leiteiras na região semiárida de Pernambuco. Além disso, a realização de pesquisas em propriedades rurais (on-farm) aproxima os produtores rurais do conhecimento científico, gerando informações e tecnologias para a tomada de decisões. Portanto, objetivouse, com este estudo, avaliar o efeito de dietas com diferentes níveis de energia na produção e na composição físico-química de leite de cabras, no consumo de nutrientes, nos parâmetros metabólicos e na relação benefício/custo de um sistema de produção de cabras leiteiras.

\section{MATERIAL E MÉTODOS}

Todos os procedimentos realizados neste experimento foram aprovados pelo Comitê de Ética no Uso de Animais - Ceua/Embrapa, sob o protocolo $n^{\circ}$ 07/2017.

O experimento foi desenvolvido na Fazenda Milano, no município de Santa Maria da Boa Vista, Pernambuco, Brasil (08 $48^{\prime} 28^{\prime \prime}$ latitude sul, 3949'32" longitude oeste e altitude de 361 metros), durante os meses de setembro e outubro de 2017. Segundo a classificação de Köppen, Santa Maria da Boa Vista é caracterizada por ter verões quentes e úmidos e invernos mornos e secos, com temperaturas de mínimas de $19^{\circ} \mathrm{C}$ e máximas de $35^{\circ} \mathrm{C}$.

Foram utilizadas nove cabras das raças Saanen e Alpina, pesadas, avaliadas quanto à produção de leite e distribuídas homogeneamente em quadrado latino triplo $3 \times 3$, sendo duas Alpinas e uma Saanen em cada quadrado, com peso corporal médio de $41,5 \pm 2,6 \mathrm{~kg}$, todas pluríparas, com idade entre 3,5 e 5,0 anos, no segundo mês de lactação. O ensaio teve duração de 60 dias, divididos em três períodos de 20 dias. Os primeiros 15 dias de cada período foram utilizados para a adaptação dos animais às dietas experimentais, e os cinco dias seguintes foram destinados à coleta de dados. Os animais foram mantidos em confinamento em baias individuais $\left(4 \mathrm{~m}^{2}\right)$ de piso batido e sombreamento natural, com comedouro, bebedouro e água à vontade. 
Avaliaram-se rações completas, contendo três níveis energéticos, correspondentes aos teores de nutrientes digestíveis totais (NDT), como a seguir: dieta 1 com $65 \%$ de NDT, visando à produção de 0,6 - 1,5kg/leite/dia (Nutrient..., 2007); dieta 2 com $70 \%$ de NDT; e dieta 3 com $75 \%$ de NDT. A alimentação foi fornecida em duas ofertas diárias, às oito horas e às 16 horas, possibilitando $20 \%$ de sobras em relação ao ofertado. A porção volumosa foi composta pela combinação de farelo de resíduo da uva e silagem de milho, na proporção 1:5, ambos produzidos na própria propriedade, constituindo $40 \%$ da matéria seca (MS) da dieta. A porção concentrada foi constituída por farelo de soja, ureia, farelo de trigo e grão de milho, correspondendo a $60 \%$ da dieta (Tab. 1 e 2), além de suplementação mineral fornecida junto à dieta.

Tabela 1. Composição químico-bromatológica (\% da matéria seca) dos concentrados e do volumoso das dietas experimentais

\begin{tabular}{lcccc}
\hline Parâmetros & C 65\% NDT & C 70\% NDT & C 75\% NDT & Volumoso \\
\hline Matéria seca & 88,37 & 95,06 & 97,13 & 61,94 \\
Matéria orgânica & 94,16 & 92,03 & 91,53 & 92,73 \\
Proteína bruta & 14,54 & 19,31 & 20,33 & 12,40 \\
Extrato etéreo & 0,83 & 2,17 & 3,67 & 2,23 \\
FDN & 42,02 & 31,29 & 24,24 & 63,31 \\
FDA & 13,22 & 8,38 & 4,15 & 24,22 \\
Lignina & 4,37 & 2,44 & 0,62 & 8,87 \\
\hline
\end{tabular}

C: Concentrado; NDT: nutrientes digestíveis totais; FDN: fibra em detergente neutro; FDA: fibra em detergente ácido.

Tabela 2. Proporção de ingredientes (\% da matéria seca) e composição químico-bromatológica das dietas experimentais

\begin{tabular}{|c|c|c|c|}
\hline Ingrediente & $65 \%$ NDT & $70 \%$ NDT & $75 \%$ NDT \\
\hline SMBU & 40 & 40 & 40 \\
\hline Farelo de soja & 1 & 5,1 & 8 \\
\hline Ureia & 0,2 & 0,2 & 0,3 \\
\hline Farelo de trigo & 57,1 & 31,6 & 3,9 \\
\hline Milho grão & 1,6 & 23 & 47,7 \\
\hline Suplemento mineral e vitamínico & 0,1 & 0,1 & 0,1 \\
\hline \multicolumn{4}{|l|}{ Parâmetro } \\
\hline Matéria seca (\% do alimento) & 77,80 & 81,81 & 83,05 \\
\hline Matéria mineral & 5,51 & 4,82 & 3,61 \\
\hline Matéria orgânica & 94,49 & 95,18 & 96,39 \\
\hline Proteína bruta & 13,68 & 16,55 & 17,16 \\
\hline Extrato etéreo & 1,39 & 2,19 & 3,09 \\
\hline FDN & 50,54 & 44,10 & 39,87 \\
\hline FDA & 17,62 & 14,72 & 12,17 \\
\hline Lignina & 6,17 & 5,01 & 3,92 \\
\hline
\end{tabular}

SMBU: silagem de milho com bagaço de uva; NDT: nutrientes digestíveis totais, FDN: fibra em detergente neutro; FDA: fibra em detergente ácido. ${ }^{1}$ Composição centesimal do sal mineral comercial Caprinofos Tortuga ${ }^{\circledR}$ : fósforo $(\mathrm{g} / \mathrm{kg}): 71,0$; cálcio $(\mathrm{g} / \mathrm{kg}): 240,0$; potássio $(\mathrm{g} / \mathrm{kg}): 28,2 ;$ magnésio $(\mathrm{mg} / \mathrm{kg}): 20,0$; enxofre $(\mathrm{g} / \mathrm{kg}): 15,0 ;$ cobalto (mg/kg): 30,0; cobre (mg/kg): 400,0; iodo $(\mathrm{mg} / \mathrm{kg}): 40,0$; manganês $(\mathrm{mg} / \mathrm{kg}): 1.350,0$; selênio $(\mathrm{mg} / \mathrm{kg}): 15,0$; ferro $(\mathrm{mg} / \mathrm{kg}): 250,0$; cromo $(\mathrm{mg} / \mathrm{kg}): 10,0$; zinco $(\mathrm{mg} / \mathrm{kg}): 1.700,0$; flúor $(\mathrm{mg} / \mathrm{kg}): 710,0$; vitamina A (UI): 135.000,0; vitamina D3 (UI): 68.000,0; vitamina E (UI): 450,0.

Ao final de cada período de coleta de dados, intervalos de 20 dias, os animais foram pesados individualmente, pela manhã, antes da primeira oferta de alimento, em balança digital portátil com gancho, suspendendo os animais, obtendo- se os pesos corporais ao início e final de cada período.

Foram realizadas três coletas de volumoso, de concentrado e das sobras, em cada período de 
coleta de dados, e as amostras foram levadas para avaliação químico-bromatológica no Laboratório de Nutrição Animal da Embrapa Semiárido. As determinações dos teores de matéria seca (MS), matéria mineral (MM), matéria orgânica $(\mathrm{MO})$, proteína bruta $(\mathrm{PB})$ e extrato etéreo (EE) dos alimentos fornecidos e das sobras foram realizadas conforme as especificações descritas na AOAC (2016): matéria seca (MS; método 967.03), matéria mineral (MM; método 942.05), proteína (PB; método 981.10), extrato etéreo (EE; método 920.29). Foram estimados os teores de fibra em detergente neutro (FDN), segundo recomendações de Mertens (2002), e os teores de fibra em detergente ácido (FDA), conforme descrição de Van Soest et al. (1991). A lignina foi determinada por meio do tratamento do resíduo de fibra em detergente ácido, com ácido sulfúrico a $72 \%$, de acordo com metodologia descrita por Silva e Queiroz (2006). O conteúdo de carboidratos totais (CT) foi estimado pela diferença: $\mathrm{CT}=100-(\mathrm{PB}+\mathrm{EE}+\mathrm{MM})$. A eficiência alimentar ( $\mathrm{kg}$ de leite $/ \mathrm{kg}$ de $\mathrm{MS}$ consumida) foi estimada pela relação entre a produção diária de leite ( $\mathrm{kg} / \mathrm{dia})$ e pelo consumo de matéria seca.

Nos últimos cinco dias de cada período, foram realizadas cinco coletas e pesagens da produção de leite, pela manhã, antes da primeira oferta de alimento, durante o período de coleta de dados. As cabras foram ordenhadas manualmente, uma vez ao dia, e o leite foi separado em recipientes específicos para cada dieta ofertada. Além disso, uma amostra de $100 \mathrm{~mL} /$ animal foi coletada, congelada e levada posteriormente para as análises laboratoriais. As análises do leite foram realizadas utilizando-se o analisador digital Master Classic Complete, da marca AKSO Brasil, determinando-se os teores de gordura, lactose, extrato seco desengordurado, proteína, densidade, condutividade e sais minerais. Antes das análises, o equipamento foi calibrado de acordo com as recomendações do fabricante (calibrado para leite de vaca). Foram analisadas 27 amostras compostas de cada animal nas três dietas e durante os três períodos de coleta de leite. A produção de leite corrigida para $3,5 \%$ de gordura foi obtida de acordo com a equação descrita por Gravert (1987): LCG $(3,5 \%)=$ 0,4337.PL + 16,218.PG, em que LCG é leite corrigido para gordura; PL, produção de leite (kg/dia); e PG, produção de gordura (kg/dia).

Amostras de sangue foram coletadas no último dia de cada período de coleta de dados, pela manhã, antes da oferta do alimento, para as dosagens de glicose, albumina e ureia. As coletas de sangue foram realizadas por venopunção da jugular, com tubos Vacutainer (10,0mL) sem anticoagulante. As amostras sanguíneas foram centrifugadas, e o soro foi armazenado em tubos Eppendorf e congelado para posterior análise laboratorial. As dosagens metabólicas foram mensuradas por espectrofotometria, por meio de kits comerciais da marca Labtest, fabricado pela Labtest Diagnósticos S.A, no Brasil, empregando-se a metodologia enzimática, seguindo-se as recomendações dos fabricantes.

Foi realizada a análise econômica considerandose os custos dos ingredientes em cada dieta alimentar e a produção de leite, que foi o fator variável, levando-se em conta a mão de obra semelhante para as dietas. Para o cálculo de custo da alimentação, considerou-se o preço por quilo de cada ingrediente e a proporção utilizada em cada dieta, da seguinte forma: $\mathrm{C}=$ Pro $\mathrm{x}$ Pre, em que: $\mathrm{C}$ é o custo do ingrediente na dieta, Pro é a proporção do ingrediente utilizado na dieta e Pre é o preço por quilo de cada ingrediente, estimado em abril de 2018. Foi realizado o levantamento do custo da alimentação durante todo o experimento, para cada animal, em relação ao valor de leite total produzido, a fim de se obter a relação benefício/custo (R $\$$ /60dias). Foi considerado o custo do litro de leite de cabra no mercado a $\mathrm{R} \$ 3,00$.

Empregou-se um delineamento em quadrado latino triplo $3 \times 3$, sendo utilizadas três dietas e três períodos, com três repetições, totalizando 27 observações para cada variável. Os dados foram inicialmente submetidos ao teste de normalidade de Kolmogorov-Smirnov, para, posteriormente, ser feita a análise de variância, seguida do teste de Tukey, a fim de se compararem os efeitos das dietas alimentares para as seguintes variáveis: peso corporal, produção e qualidade físicoquímica do leite, dosagens metabólicas, consumo de matéria seca e de nutrientes nas dietas. Utilizou-se o pacote estatístico SAS University (SAS, 2017) e as diferenças foram consideradas significativas quando $\mathrm{P}<0,05$. 


\section{Vicente et al.}

\section{RESULTADOS E DISCUSSÃO}

Os consumos de matéria seca, matéria orgânica, fibra em detergente neutro, fibra em detergente ácido, proteína bruta, matéria mineral e eficiência alimentar foram influenciados $(\mathrm{P}<0,05)$ pelos teores de NDT na dieta (Tab. 3).

Os consumos de matéria seca (MS), proteína bruta e matéria mineral foram superiores
$(\mathrm{P}<0,05)$ para as cabras alimentadas com dietas contendo $70 \%$ e $75 \%$ de NDT em comparação às que receberam a dieta com $65 \%$ de NDT (Tab. 3). As cabras alimentadas com maiores níveis de energia consumiram maior quantidade de MS, indicando que a qualidade da dieta ofertada tem efeito direto no consumo e na aceitabilidade dos animais.

Tabela 3. Consumo de matéria seca e de nutrientes e eficiência alimentar de cabras em lactação alimentadas com dietas contendo diferentes níveis de energia

\begin{tabular}{lccccc}
\hline \multicolumn{1}{c}{ Parâmetro } & \multicolumn{3}{c}{ NDT na dieta $(\%$ da MS) } & & \\
\hline & $65 \%$ NDT & $70 \%$ NDT & $75 \%$ NDT & P & EPM \\
\hline Matéria seca (kg/dia) & $1,62^{\mathrm{b}}$ & $1,85^{\mathrm{a}}$ & $1,82^{\mathrm{a}}$ & 0,02 & 0,06 \\
Matéria orgânica (kg/dia) & $1,52^{\mathrm{b}}$ & $1,71^{\mathrm{a}}$ & $1,68^{\mathrm{ab}}$ & 0,04 & 0,05 \\
FDN (kg/dia) & $0,82^{\mathrm{a}}$ & $0,82^{\mathrm{ab}}$ & $0,73^{\mathrm{b}}$ & 0,03 & 0,02 \\
FDA (kg/dia) & $0,29^{\mathrm{a}}$ & $0,27^{\mathrm{a}}$ & $0,22^{\mathrm{b}}$ & 0,0001 & 0,01 \\
Proteína bruta (kg/dia) & $0,22^{\mathrm{b}}$ & $0,31^{\mathrm{a}}$ & $0,31^{\mathrm{a}}$ & 0,0001 & 0,01 \\
Matéria mineral (kg/dia) & $0,10^{\mathrm{b}}$ & $0,14^{\mathrm{a}}$ & $0,15^{\mathrm{a}}$ & 0,0001 & 0,01 \\
Carboidratos totais (kg/dia) & 0,45 & 0,49 & 0,48 & 0,09 & 0,01 \\
Eficiência alimentar (leite/MS kg) & $0,49^{\mathrm{b}}$ & $0,56^{\mathrm{ab}}$ & $0,63^{\mathrm{a}}$ & 0,02 & 0,03 \\
\hline
\end{tabular}

Médias seguidas de letras diferentes $\left({ }^{\mathrm{a}, \mathrm{b}}\right)$ na mesma linha indicam diferença significativa $(\mathrm{P}<0,05)$ pelo teste de Tukey. NDT: nutrientes digestíveis totais; MS: matéria seca; P: probabilidade; EPM: erro-padrão da média; FDN: fibra em detergente neutro; FDA: fibra em detergente ácido.

Outra explicação para o menor consumo de MS nas cabras alimentadas com $65 \%$ de NDT é o maior teor $(\mathrm{P}<0,05)$ de FDN e FDA nessa dieta. $\mathrm{O}$ aumento no teor das fibras pode limitar o consumo de alimentos pelo enchimento ruminal. Mertens (2002) relatou que o consumo de MS pode ser atribuído à composição das dietas, ou seja, houve aumento do consumo de MS quando houve redução de FDN à medida que a silagem de milho foi substituída pela polpa cítrica $(6 \%$, $12 \%$ ou $24 \%$ da MS).

O maior consumo de proteína bruta nas dietas com $70 \%$ e $75 \%$ de NDT foi em decorrência da proporção desse ingrediente na dieta (Tab. 1) e do maior consumo de MS. Esses resultados corroboram os dados de Rodrigues et al. (2006), que avaliaram dietas com diferentes níveis de energia líquida (1,4 e 1,6Mcal EL/kg de MS) em cabras Alpinas em lactação produzindo 2,88 e 3,55 litros de leite/dia, respectivamente, e observaram que os animais alimentados com o maior nível de energia apresentaram maior consumo de MS (2,03kg/dia). Segundo os mesmos autores, o maior teor de energia líquida estimulou o consumo e a aceitabilidade dos animais às dietas alimentares.

O maior $(\mathrm{P}<0,05)$ peso corporal final nas cabras alimentadas com $75 \%$ de NDT em comparação às cabras alimentadas com $65 \%$ e $70 \%$ de NDT (Fig. 1) foi decorrente do maior consumo de MS e de nutrientes pelos animais. Além disso, ao longo do experimento, as cabras alimentadas com as dietas $65 \%$ e $70 \%$ de NDT apresentaram perda de peso $(\mathrm{P}<0,05)$ e mobilização das reservas corporais para sustentar a lactação, enquanto as cabras alimentadas com $75 \%$ de NDT mantiveram o peso corporal (Fig. 1). Silva et al. (1999) também registraram maior ganho de peso corporal em animais que receberam dietas com maiores teores de energia, tendo como consequência menor mobilização de reservas corporais para a produção de leite.

O menor aporte de nutrientes observado nas dietas com $65 \%$ e $70 \%$ de NDT promoveu um possível balanço energético negativo (BEN), o que alterou os mecanismos de mobilização de energia e contribuiu para a perda de peso das cabras com essas dietas. No segundo mês de 
lactação, o BEN ocorre porque a demanda de nutrientes é maior que a ingestão de alimentos, e isso ocasiona aumento na taxa de lipólise, promovendo a liberação de glicerol e ácidos graxos não esterificados utilizados pelos tecidos como fonte de energia e precursores de gordura do leite (Rodrigues et al., 2007). Na dieta com
$75 \%$ de NDT, o maior aporte de nutrientes observado, além de sustentar maior produção leiteira, foi também direcionado para a síntese de tecidos corporais, promovendo maior peso corporal.

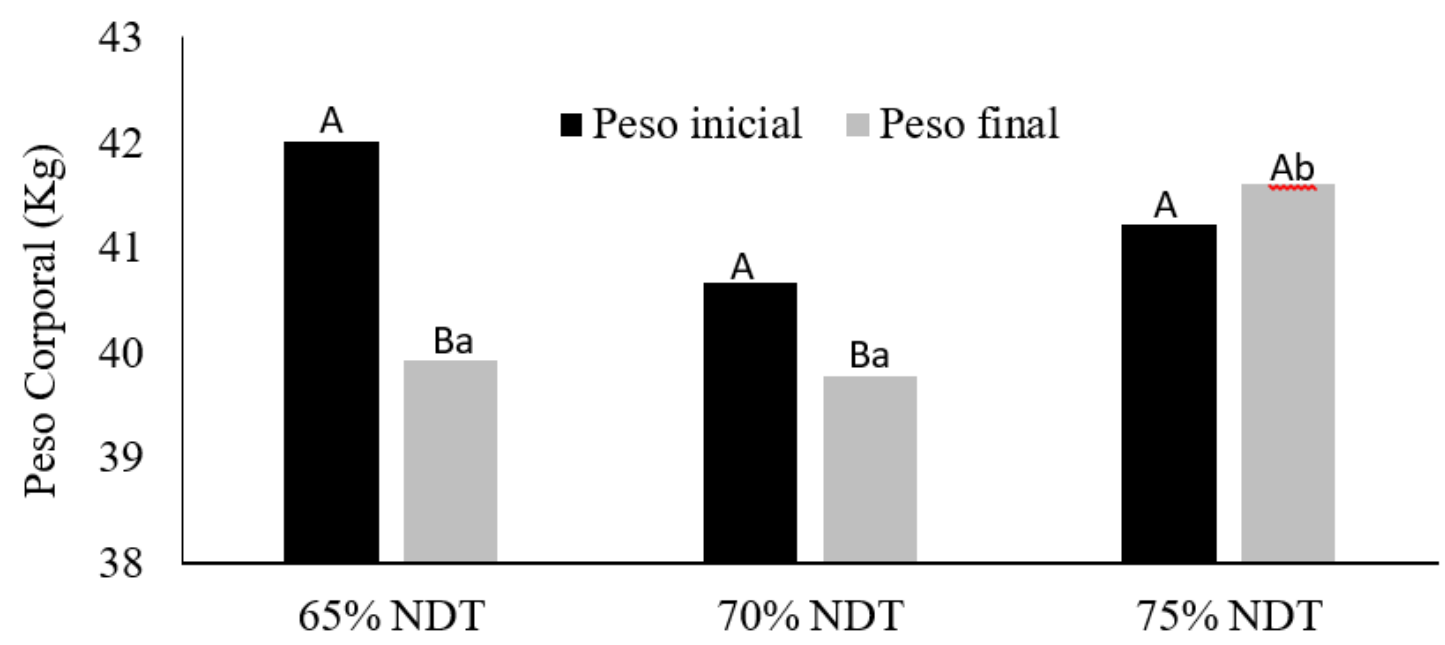

Dietas experimentais

Letras maiúsculas $(\mathrm{A}, \mathrm{B})$ indicam diferenças $(\mathrm{P}<0,05)$ no peso corporal dentro do mesmo nível de NDT. Letras minúsculas $(a, b)$ indicam diferenças no peso corporal final $(\mathrm{P}<0,05)$ entre os diferentes níveis de NDT.

Figura 1. Peso corporal inicial e final de cabras em lactação alimentadas com dietas contendo diferentes níveis de nutrientes digestíveis totais (NDT).

Tabela 4. Produção e composição do leite total, média e corrigida a 3,5\% de gordura, teores de gordura, lactose, extrato seco desengordurado, densidade, sais e condutividade de leite de cabras alimentadas com dietas contendo diferentes níveis de energia

\begin{tabular}{lccccc}
\hline \multicolumn{1}{c}{ NDT na dieta (\% da MS) } & & \\
\hline \multicolumn{1}{c}{ Parâmetro } & $65 \%$ NDT & $70 \%$ NDT & $75 \%$ NDT & P & EPM \\
\hline Produção total leite (kg/60 dias) & $46,80^{\mathrm{b}}$ & $61,85^{\mathrm{a}}$ & $69,60^{\mathrm{a}}$ & 0,0005 & 0,07 \\
Produção de leite (kg/dia) & $0,78^{\mathrm{b}}$ & $1,03^{\mathrm{a}}$ & $1,16^{\mathrm{a}}$ & 0,0005 & 0,07 \\
PLC 3,5\% (kg/dia) & 1,18 & 1,29 & 1,20 & 0,82 & 0,09 \\
Gordura (\%) & 2,58 & 2,60 & 2,12 & 0,70 & 0,26 \\
Lactose (\%) & 4,22 & 4,49 & 4,59 & 0,77 & 0,20 \\
Proteína bruta (\%) & 2,53 & 2,33 & 3,28 & 0,78 & 0,13 \\
Extrato seco desengordurado (\%) & 7,62 & 8,12 & 8,34 & 0,75 & 0,36 \\
Densidade (\%) & 27,69 & 28,61 & 30,80 & 0,69 & 1,40 \\
Sais (\%) & 0,64 & 0,68 & 0,70 & 0,75 & 0,03 \\
Condutividade (mS/cm) & 1,43 & 1,39 & 1,46 & 0,34 & 0,02 \\
\hline
\end{tabular}

Médias seguidas de letras diferentes $\left({ }^{a}, b\right)$ indicam diferença significativa $(\mathrm{P}<0,05)$ pelo teste de Tukey. P: probabilidade; EPM: erro-padrão da média; NDT: nutrientes digestíveis totais; MS: matéria seca; PLC: produção de leite corrigida, equação descrita por Gravert (1987): LCG (3,5\%) = 0,4337.PL + 16,218.PG, em que LCG é leite corrigido para gordura; PL, produção de leite (kg/dia); e PG, produção de gordura (kg/dia). 
A produção média diária e a produção total de leite durante os 60 dias experimentais foram superiores $(\mathrm{P}<0,05)$ nas cabras alimentadas com dietas contendo $70 \%$ e $75 \%$ de NDT, quando comparadas com as cabras que receberam $65 \%$ de NDT (Tab. 4). A maior produção de leite das cabras alimentadas com dietas contendo $70 \%$ e $75 \%$ de NDT é decorrente dos maiores consumos de MS, PB e MM (Tab. 3). Esse fato também explica o porquê de a eficiência alimentar nas cabras alimentadas com $75 \%$ de NDT ser superior $(\mathrm{P}<0,05)$ à das cabras suplementadas com $65 \%$ de NDT.

A produção de leite está diretamente relacionada à quantidade total de energia consumida (Hussain et al., 1996). Portanto, o aumento no aporte energético, provavelmente, favoreceu a produção de propionato em relação ao acetato no rúmen, aumentando a relação propionato:acetato. O propionato é precursor da glicose que é utilizada na síntese do leite e, consequentemente, promove aumento no volume de leite produzido (Branco et al., 2010; Nascimento et al., 2017).

A produção de leite corrigida (PLC) para 3,5\% de gordura e a composição físico-química do leite não foram influenciadas $(\mathrm{P}<0,05)$ pelos teores energéticos das dietas (Tab. 4). Resultados semelhantes foram obtidos por Branco et al. (2010), que avaliaram diferentes níveis de fibra $(19 \%, 27 \%, 35 \%, 42 \%$ e $48 \%$ de FDN) e energia $(72,8 \% ; 68,8 \% ; 64,7 \% ; 60,7 \%$ e $57,7 \%$ de NDT) na produção e na composição de leite de cabras leiteiras e não observaram diferença significativa nas porcentagens de gordura, proteína e lactose em relação aos diferentes níveis de fibra e energia. De forma semelhante, Rodrigues et al. (2007) avaliaram a produção e a composição de leite de cabras alimentadas com diferentes razões de energia líquida e proteína bruta (7,32\%; $10,89 \% ; 12,93 \%$; e $14,89 \%$ ) e não observaram diferença significativa entre os componentes do leite (gordura, lactose, extrato seco desengordurado, proteína e ureia), mesmo resultando em maiores produções de leite nos maiores níveis nutricionais.
Diversos fatores, como consumo de matéria seca, ingestão de água, estágio de lactação e sanidade dos animais, podem afetar a concentração de lactose, gordura e proteínas (Goetsch et al., 2001). Neste estudo, as cabras foram avaliadas entre o segundo e o quarto mês de lactação, sendo observada uma redução na produção de leite no decorrer do período experimental. Durante redução da curva de lactação e, consequentemente, queda da produção do leite, verifica-se que o leite torna-se mais rico em sólidos totais, com aumento da concentração de seus constituintes físico-químicos.

Embora o teor de gordura no leite seja o nutriente que está mais propenso a receber influência do tipo de alimentação, não foi observada diferença $(\mathrm{P}<0,05)$ de porcentagem de gordura entre os leites produzidos por animais alimentados com dietas com diferentes níveis energéticos. Esse efeito pode ser explicado pela concentração volumoso:concentrado, que foi de 40:60. Portanto, a porcentagem do volumoso $(40 \%)$ foi menor que a de concentrado $(60 \%)$ e, provavelmente, não foi suficiente para afetar as concentrações de gordura do leite. Esses resultados corroboram os de Nascimento et al. (2017), que avaliaram níveis de energia (65\%, $75 \%$ e $85 \%$ de NDT) em cabras mestiças de aptidão leiteira e não observaram diferença significativa no teor de gordura $(3,16 \% ; 3,28 \%$; $3,86 \%$ e $3,90 \%$ ) no $60^{\circ}$ dia de experimento.

Neste estudo, outra possível explicação para a não diferença $(\mathrm{P}>0,05)$ entre as porcentagens de gordura, lactose e extrato seco desengordurado foi a pequena diferença entre os níveis de energia consumida $(65 \%, 70 \%$ e $75 \%$ de NDT) das dietas experimentais. As concentrações plasmáticas de glicose, albumina e ureia não apresentaram diferenças significativas $(\mathrm{P}>0,05)$ entre as dietas experimentais (Tab. 5), embora os teores $(\mathrm{mg} / \mathrm{dL})$ desses parâmetros avaliados se mantivessem dentro da normalidade para cabras em lactação.

Tabela 5. Metabólicos plasmáticos (glicose, albumina e ureia) de cabras em lactação alimentadas com dietas contendo níveis crescentes de energia

\begin{tabular}{lccccc}
\multicolumn{1}{c}{ Parâmetro } & $65 \%$ NDT & $70 \%$ NDT & $75 \%$ NDT & P & EPM \\
\hline Glicose $(\mathrm{mg} / \mathrm{dL})$ & 74,62 & 78,19 & 74,45 & 0,89 & 3,67 \\
Albumina (g/L) & 2,55 & 2,66 & 2,80 & 0,28 & 0,09 \\
Ureia (mg/dL) & 35,90 & 33,64 & 39,88 & 0,52 & 2,01 \\
\hline
\end{tabular}

NDT: nutrientes digestíveis totais; P: probabilidade, EPM: erro-médio padrão da média 
Em caprinos, as concentrações plasmáticas de glicose após suplementação com $220 \mathrm{~g}$ de farelo de milho/cabra permaneceram inalteradas, evidenciando a capacidade dos ruminantes em manter a glicemia após a suplementação com diferentes níveis de energia (Nogueira et al., 2017). De forma semelhante, Maia et al. (2010) avaliaram diferentes níveis de óleos de mamona e licuri, com valores de energia metabolizável de $1,93,2,04$ e 2,11kcal $/ \mathrm{kg}$, sobre os parâmetros metabólicos (glicose e ureia) em cabras leiteiras e observaram que não houve diferença significativa entre os tratamentos.

As alterações nas concentrações de ureia plasmática em cabras estão relacionadas diretamente com o conteúdo de amônia no rúmen, assim a sua utilização depende da atividade metabólica nos microrganismos ruminais. As concentrações de ureia no sangue dependem diretamente do valor energético, das proteína na dieta e de suas interações (Gonzáles e Scheffer, 2003). No presente estudo, apesar de ocorrido um maior consumo de proteína bruta nos animais alimentados com dietas com $70 \%$ e $75 \%$ de NDT, não houve diferença nas concentrações plasmáticas de ureia entre as dietas experimentais.

As concentrações de albumina apresentaram valores dentro do normal para caprinos e não foram alteradas pelos diferentes níveis de NDT da dieta. A albumina é o indicador mais importante para determinar o estado nutricional proteico, pois representa uma importante reserva proteica, assim o inadequado consumo de proteína e energia resulta em valores baixos de albumina (Wittwer et al., 1993).

O custo da dieta variou de $\mathrm{R} \$ 0,64$ a $\mathrm{R} \$ 0,74$ por quilo de matéria natural (Tab. 6). Sendo de $\mathrm{R} \$$ 3,00 o valor comercial do litro de leite, observouse que a receita da produção de leite, durante os 60 dias experimentais, variou de $\mathrm{R} \$ 141,90$ a $\mathrm{R} \$$ 210,51. A análise econômica das dietas registrou resultados economicamente insatisfatórios porque não foram contabilizados os custos da mão de obra e dos utensílios para ordenha. No entanto, a relação benefício/custo foi positiva, variando de $1,18 \%$ a $1,52 \%$, sendo a melhor opção de uso a dieta com $75 \%$ de NDT, pois, para cada $\mathrm{R} \$ 1,00$ no custo investido na alimentação, houve $\mathrm{R} \$ 1,52$ de retorno financeiro (Tab. 6).

O investimento no maior valor energético nas dietas das cabras em lactação aumentou o custo, todavia proporcionou maior produção leiteira e maior eficiência alimentar, os quais foram os fatores que propiciaram a melhor relação benefício/custo na dieta contendo $75 \%$ de NDT para as cabras em lactação.

Tabela 6. Custo da dieta, custo total pelo consumo, receita da produção de leite e relação benefício/custo da produção de leite de cabras alimentadas com dietas contendo diferentes teores de energia

\begin{tabular}{lccc}
\hline \multicolumn{1}{c}{ Parâmetro } & \multicolumn{3}{c}{ NDT na dieta (\% da MS) } \\
\hline Custo da dieta (R\$/kg de MN) & $65 \%$ NDT & $70 \%$ NDT & $75 \%$ NDT \\
Custo total pelo consumo (R $\$$ /60 dias) & 0,64 & 0,69 & 0,74 \\
Receita da produção de leite (R\$/60 dias) & 119,42 & 142,20 & 138,60 \\
Relação benefício/custo $(\%)$ & 141,90 & 185,55 & 210,51 \\
\hline
\end{tabular}

NDT: nutrientes digestíveis totais; MN: matéria natural. Preço dos ingredientes ( $\mathrm{R} \$ \mathrm{~kg}$ ): volumoso: 0,45; soja: 1,84; farelo de trigo: 0,73; milho: 0,76; ureia: 7,33. Litro de leite: $\mathrm{R} \$ 3,00$.

\section{CONCLUSÃO}

Cabras alimentadas com maiores níveis de energia, de $70 \%$ e $75 \%$ de NDT na dieta total, apresentam maior produção de leite e melhor eficiência alimentar. $\mathrm{Na}$ avaliação on-farm, os níveis de energia não influenciaram na composição físico-química do leite, no consumo de água e nos parâmetros sanguíneos dos animais. A dieta com $75 \%$ de NDT apresenta melhor relação benefício/custo, pois, para cada $\mathrm{R} \$ 1,00$ no custo investido na alimentação, houve $\mathrm{R} \$ 1,52$ de retorno financeiro. 


\section{REFERÊNCIAS}

ARAÚJO, T.F.; FERREIRA, E.G.; SOUZA, J.R.M. et al. Development of yogurt sundae like made from goat milk flavored with passion fruit. Rev. Inst. Latic. Cândido Tostes, v.67, p.48-54, 2012.

BRANCO, R.H.; RODRIGUES, M.T.; SILVA, M.M.C. et al. Efeito dos níveis de fibra da forragem sobre o consumo, a produção e a eficiência de utilização de nutrientes em cabras lactantes. Rev. Bras. Zootec., v.39, p.2477-2485, 2010.

COSTA, R.G.; QUEIROGA. R.C.; PEREIRA, R.A.G. Influência do alimento na produção e qualidade do leite de cabra. Rev. Bras. Zootec., v.38, p.210-216, 2009.

GOETSCH, A.L.; DETWEILER, G.; SAHLU, T. et al. Dairy goat performance with different dietary concentrate levels in late lactation. Small Ruminant Res., v.41, p.117-125, 2001.

GONZÁLEZ, F.H.D.; SCHEFFER, J.F.S. Perfil sanguíneo: ferramenta de análise clínica, metabólica e nutricional. SIMPÓSIO DE PATOLOGIA CLÍNICA VETERINÁRIA, Porto Alegre, 2003. Anais... Porto Alegre: UFRGS, 2003. v.1, p.73-88.

GRAVERT, H.O. Breeding of dairy cattle. In: VAN ARENDONK, J.A.M.; LIINAMO, A.E. Dairy cattle production. New York: Elsevier Science, 1987. p.35-76.

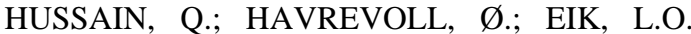
Effect of type of roughage on feed intake, milk yield and body condition of pregnant goats. Small Ruminant Res., v.22, p.131-139, 1996.

MAIA, M.O.; QUEIROGA, R.C.E.; MEDEIROS, A.N. et al. Consumo, digestibilidade de nutrientes e parâmetros sanguíneos de cabras mestiças moxotó Moxotó suplementadas com óleos de licuri ou mamona. Ciênc. Rural, v.40, p.149-155, 2010.

MERTENS, D.R. Gravimetric determination of amylase-treated neutral detergent fiber in feeds with refluxing in beaker or crucibles: collaborative study. J. Assoc. Off. Anal. Chem. Int., v.85, p.12171240, 2002.

NASCIMENTO, T.V.C.; ALMEIDA JUNIOR, W.L.G.; LOPES JUNIOR, E.S.L. et al. Physical and chemical characteristics of milk from goats supplemented with different levels of total digestible nutrients in the dry period. Acta Sci. Anim. Sci., v.39, p.429-435, 2017.
NOGUEIRA, D.M.; ESHTAEBA, A.; CAVALIERI J. et al. A. Short-term supplementation with maize increases ovulation rate in goats when dietary metabolizable energy provides requirements for both maintenance and 1.5 times maintenance. Theriogenology, v.89, p.97$105,2017$.

NUTRIENT requirements of small ruminants: sheep, goats, cervids, and new world camelids. Washintgton: National Academy of Science, 2007. $347 \mathrm{p}$.

RODRIGUES, C.A.F.; RODRIGUES, M.T.; BRANCO, R.H. Consumo, digestibilidade e produção de leite de cabras leiteiras alimentadas com dietas contendo diferentes níveis de proteína bruta e energia líquida. Rev. Bras. Zootec., v.36, p.1658-1667, 2007.

RODRIGUES, C.A.F.; RODRIGUES, M.T.; BRANCO, R.H. et al. Influência da condição corporal e da concentração de energia nas dietas no periparto sobre a performance de cabras em lactação. Rev. Bras. Zootec., v.35, p.1560-1567, 2006.

SAS university. SAS/IML $® 14.1$ user's guide. Cary, NC: SAS Institute Inc., 2017.

SILVA, D.J.; QUEIROZ, A.C. Análise de alimentos: métodos químicos e biológicos. 3.ed. Viçosa, MG: UFV, 2006. 235p.

SILVA, J.H.V.; RODRIGUES, M.T.; CAMPOS, J. Desempenho de cabras leiterias recebendo dietas com diferentes relações volumoso:concentrado. Rev. Bras. Zootec., v.28, p.1412-1418, 1999.

VAN SOEST, P.J.; ROBERTSON, J.B.; LEWIS, B.A. Methods for dietary fiber, neutral detergent fiber, and nonstarch polysaccharides in relation to animal nutrition. J. Dairy Sci., v.74, p.3583-3597, 1991.

VILAR, A.L.T.; COSTA, R.G.; MEDEIROS, A.N. et al. Efeito da ordem de parição e do período de ordenha na produção e composição do colostro e do leite de transição de cabras Saanen. Rev. Bras. Zootec., v.37, p.1674-1678, 2008.

WITTWER, F.; REYES, J.M.; OPITZ, H. et al. Determinación de urea em muestras de leche de rebaños bovinos para el dignostico de desbalance nutricional. Arch. Med. Vet., v.25, p.165-172, 1993.

ZAMBOM, M.A.; ALCALDE, C.R.; SILVA, K.T. et al. Ingestão, digestibilidade das rações e produção de leite de cabras Saanen submetidas a diferentes relações volumoso:concentrado na ração. Rev. Bras. Zootec., v.34, p.2505-2514, 2005. 